\title{
INFLUÊNCIA DE IMPLEMENTOS DE PREPARO E DE NÍVEIS DE COMPACTAÇÃO SOBRE ATRIBUTOS FÍSICOS DO SOLO E ASPECTOS AGRONÔMICOS DA CULTURA DO MILHO
}

Doi:http://dx.doi.org/10.1590/1809-4430-Eng.Agric.v36n2p 367-376/2016

\section{MILTON A. DEPERON JÚNIOR ${ }^{1}$, HIDEO DE J. NAGAHAMA ${ }^{2}$, NELCI OLSZEVSKI ${ }^{3}$, JORGE W. CORTEZ ${ }^{4}$, ELDER B. DE SOUZA ${ }^{5}$}

\begin{abstract}
RESUMO: Os sistemas de preparo do solo e o aumento do tráfego nas áreas agrícola têm contribuído para o aumento da compactação do solo e diminuição da produtividade das culturas. Assim, objetivou-se avaliar a influência de implementos de preparo do solo e de níveis de compactação sobre atributos físicos de Argissolo Amarelo distrófico típico, textura arenosa, e os impactos nos atributos agronômicos da cultura do milho. Os tratamentos foram constituídos por três implementos de preparo do solo $\left(\mathrm{IP}_{1}=\right.$ grade aradora; $\mathrm{IP}_{2}=$ arado de aivecas, e $\mathrm{IP}_{3}=$ escarificador $)$ e quatro níveis de compactação $\left(\mathrm{NC}_{0}=\right.$ solo não trafegado; $\mathrm{NC}_{3}=3$ passadas; $\mathrm{NC}_{6}=6$ passadas, $\mathrm{e}$ $\mathrm{NC}_{9}=9$ passadas de trator). No solo, foram avaliados os atributos: densidade do solo, porosidade total e resistência mecânica à penetração, nas profundidades de $0,00-0,10 ; 0,10-0,20 ; 0,20-0,30 \mathrm{e}$ 0,30-0,40 m; e, na cultura, foram avaliados a matéria seca das plantas e de raízes e a produtividade de grãos. Os implementos de preparo do solo influenciaram sobre a densidade do solo e a porosidade total na camada de $0,00-0,10 \mathrm{~m}$. Os níveis de compactação provocaram aumento da resistência à penetração até à profundidade de $0,30 \mathrm{~m}$. $\mathrm{O}$ aumento da resistência à penetração acima de 1,53 MPa reduziu linearmente a matéria seca de plantas e a produtividade de grãos de milho, e acima de 2,18 MPa reduziu a matéria seca de raízes.
\end{abstract}

PALAVRAS-CHAVE: produtividade de grãos, resistência à penetração de raízes, Zea mays.

\section{TILLAGE MACHINER Y AND COMPACTION LEVEL INFLUENCE ON SOIL PHYSICAL PROPERTIES AND CORN AGRONOMIC ASPECTS}

\begin{abstract}
Soil tillage and increased traffic in farming areas have contributed to a higher soil compaction and decreased crop yields. Thus, we aimed at assessing the influence of tillage implement types and compaction levels on physical properties of a Yellow Argisol (Ultisol) and further effects on corn agronomic traits. The treatments consisted of three tillage implements $\left(\mathrm{IP}_{1}=\right.$ disc harrow, $\mathrm{IP}_{2}=$ moldboard plow and $\mathrm{IP}_{3}=$ chisel plow $)$ and four levels of compaction $\left(\mathrm{NC}_{0}=\right.$ no traffic soil; $\mathrm{NC}_{3}=3$ passes; $\mathrm{NC}_{6}=6$ passes and $\mathrm{NC}_{9}=9$ passes by a tractor). We evaluated the following soil properties: soil bulk density, total porosity and mechanical resistance to penetration at the depth ranges of $0.00-0.10 ; 0.10-0.20 ; 0.20-0.30$ and $0.30-0.40 \mathrm{~m}$. Regarding the corn plants, we assessed plant and root dry matter as well as grain yield. The results showed that tillage implements had influence on soil density and total porosity at the layer of $0.00-0.10 \mathrm{~m}$. Furthermore, the compaction levels increased soil mechanical resistance to penetration at a depth of $0.30 \mathrm{~m}$. We also observed that an increase above $1.53 \mathrm{MPa}$ in soil resistance to penetration reduced linearly plant dry matter and grain yield; and when it was above $2.18 \mathrm{MPa}$, root dry matter was reduced too.
\end{abstract}

KEYWORDS: grain yield, resistance to root penetration, Zea mays.

\footnotetext{
${ }^{1}$ Eng ${ }^{\circ}$ Agrônomo, Mestre, Egresso da Universidade Fe deral do Vale do São Francisco - UNIVASF, Juazeiro/BA, miltondeperon@gmail.com

${ }^{2}$ Eng $^{\circ}$ Agrônomo, Mestre, Universidade Federal do Vale do São Francisco - UNIVASF, Juazeiro/B A, hideo.nagahama@univasf.edu.br

${ }^{3}$ Eng $^{\circ}$ Agrônoma, Profa. Doutora, Colegiado de En genharia Agrícola e Ambiental, Universidade Fe deral do Vale do São Francisco UNIVASF, Juazeiro/BA, nelci.olszevski@gmail.com

${ }^{4}$ Eng $^{\mathrm{o}}$ Agrônomo, Prof. Doutor, Faculdade de Ciências Agrárias, Universida de Fe deral da Grande Dourados - UFGD, Dourados/ MS, Fone: (67) 3410-2432, jorge.cortez@yahoo.com.br

${ }^{5}$ Eng $^{\circ}$ Agrônomo, Egresso da Universidade Federal do Vale do São Francisco - UNIVASF, Petrolina/PE, elder.barboza@hotmail.com

Recebido pelo Conselho Editorial em: 18-8-2015

Aprovado pelo Conselho Editorial em: 11-2-2016
} 


\section{INTRODUÇÃO}

O preparo mecanizado do solo é realizado com a função de melhorar e criar condições favoráveis à germinação e ao crescimento radicular das culturas. Os métodos de preparo podem variar desde aqueles que causam intensa mobilização do solo, como o preparo convencional, até aos chamados preparos conservacionistas. Em função do trabalho mecânico, podem ocorrer alterações nos atributos do solo, e estas alterações podem ser mais expressivas nos atributos físicos da camada mais superficial, principalmente em virtude do tráfego de máquinas e implementos agrícolas em condições inadequadas de manejo (VALICHESKI et al., 2012).

Dentre os atributos do solo que podem sofrer alterações estão a resistência à penetração, a densidade, a porosidade, que está relacionada com o estado de compactação, que pode causar dificuldades ao desenvolvimento das raízes e acarretar perda de produtividade e de gradação do solo, devendo ser quantificada, monitorada e corrigida para limites aceitáveis; principalmente quando os valores críticos são obtidos próximos à capacidade de campo (ANDRADE et at., 2013).

Assim, a busca por valores que ind iquem restrições ao crescimento das raízes e diminuição de produtividade torna-se essencial para o sucesso da exploração agrícola (MONTANARI et al., 2013) e, de acordo com REINERT et al. (2008) e BEUTLER et al. (2009), a resistência à penetração do solo pode restringir o desenvolvimento radicular do milho, e diversos trabalhos são desenvolvidos com o intuído de determinar limites críticos ao desenvolvimento da cultura.

LIMA et al. (2010) lembram que a resistência à penetração descreve a resistência física que o solo submete as raízes em crescimento; portanto, tendo grande influência sobre a produtividade nas culturas, uma vez que, a produtividade das culturas e o crescimento radicular variam de forma inversamente proporcional ao valor de resistência à penetração (TOIGO et al., 2015).

Desse modo, objetivou-se avaliar a influência de implementos de preparo do solo e de níveis de compactação sobre atributos físicos de Argissolo Amarelo distrófico típico, textura arenosa, e os impactos em atributos agronômicos do milho.

\section{DESCRIÇÃO DO ASSUNTO}

O trabalho foi desenvolvido em Argissolo Amarelo distrófico típico, textura arenosa (EMBRAPA, 2013), localizado no Câmpus de Ciências Agrárias $\left(9^{\circ} 19^{\prime} 10^{\prime}\right.$ ' de latitude sul e 40³3' 39' de longitude oeste, altitude média de 376 m) da Universidade Federal do Vale do São Francisco (UNIVASF), em Petrolina-PE. A área encontrava-se em pousio há sete anos e possui sistema de irrigação por aspersão convencional em malha fixa. A irrigação da cultura seguiu a demanda evaporativa em função da fase fenológica da cultura, aplicando-se um total de $590 \mathrm{~mm}$.

Foi avaliada a composição granulométrica e as umidades gravimétricas (US) durante a aplicação dos tratamentos, implementos de preparo do solo e níveis de compactação, bem como durante a avaliação dos atributos físicos do solo, principalmente para a resistência à penetração, uma vez que esta foi coletada com umidade gravimétrica próxima ao ponto de murcha permanente (Tabela 1).

Para o desenvolvimento das atividades agrícolas, utilizaram-se o trator modelo 785 TDA, com $55,20 \mathrm{~kW}$ (75 cv) de potência, pneus dianteiros 12.4 - $24 \mathrm{R} 1$ e traseiros 18.4 - $30 \mathrm{R} 1$, massa de $3,5 \mathrm{Mg}$, trabalhando a uma velocidade de $3,88 \mathrm{~km} \mathrm{~h}^{-1}$, e os equipamentos de preparo: (a) grade leve em tandem modelo: GH, fabricada em 1999, com sete discos em cada seção (quatro), sendo recortados na dianteira, com $0,51 \mathrm{~m}$ de diâmetro, e lisos na traseira com mesmo diâmetro, e distância entre discos de $0,19 \mathrm{~m}$, largura de $2,62 \mathrm{~m}$, massa de $528 \mathrm{~kg}$ e profundidade de trabalho de 0,10 m; (b) grade leve off-set com sete discos recortados de 0,61 m de diâmetro (24"), modelo: ATCR, fabricada em 2005, e distância entre discos de $0,23 \mathrm{~m}$, largura de 1,50 m, massa de $1.094 \mathrm{~kg}$ e profundidade de trabalho de $0,18 \mathrm{~m}$; (c) arado de aivecas reversível, com duas aivecas recortadas de 0,41 m de comprimento (16"), modelo $\mathrm{ARH}^{2}$, fabricado em 1995, massa de $570 \mathrm{~kg}$ e profundidade de trabalho até $0,40 \mathrm{~m}$; (d) escarificador com três hastes espaçadas de $0,34 \mathrm{~m}$, ponteira estreita de 0,05 m modelo: AST, fabricado em 2005, largura total de 1,20 m, massa de 295 
$\mathrm{kg}$ e profundidade de trabalho até $0,35 \mathrm{~m}$; e (e) semeadora-adubadora com quatro linhas, que possui sistema de distribuição de sementes tipo dosador horizontale haste sulcadora para adubo.

TABELA 1. Composição granulométrica, umidade gravimétrica do solo (US) no momento do preparo do solo, da aplicação dos níveis de compactação e da coleta de dados dos atributos físicos do Argissolo Amarelo. Particle size distribution, gravimetric water content at tillage time under different compaction levels of samples used for evaluation of physical properties of a Yellow Argisol (Ultisol).

\begin{tabular}{|c|c|c|c|c|c|c|}
\hline Profund idade & Argila & Areia & Silte & $\begin{array}{c}\text { US: Preparo } \\
\text { do solo }\end{array}$ & $\begin{array}{l}\text { US: Níveis de } \\
\text { compactação }\end{array}$ & $\begin{array}{l}\text { US: Atributos } \\
\text { físicos do solo }\end{array}$ \\
\hline $\mathrm{m}$ & \multicolumn{3}{|c|}{ - - $\mathrm{kg} \mathrm{kg}^{-1}$} & \multicolumn{3}{|c|}{ 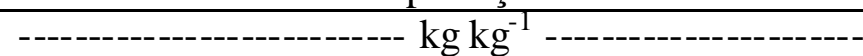 } \\
\hline $0,00-0,10$ & 0,09 & 0,88 & 0,03 & 0,11 & 0,09 & 0,08 \\
\hline $0,10-0,20$ & 0,10 & 0,88 & 0,02 & 0,10 & 0,09 & 0,09 \\
\hline $0,20-0,30$ & 0,08 & 0,85 & 0,07 & 0,09 & 0,08 & 0,07 \\
\hline $0,30-0,40$ & 0,14 & 0,81 & 0,05 & 0,07 & 0,08 & 0,08 \\
\hline
\end{tabular}

Capacidade de campo: $0,12 \mathrm{~kg} \mathrm{~kg}^{-1}$ e ponto de murcha permanente de: $0,05 \mathrm{~kg} \mathrm{~kg}^{-1}$.

O delineamento experimental utilizado foi em blocos casualizados (DBC), em esquema de parcelas subdivididas, com quatro repetições, sendo dispostos nas parcelas os implementos de preparo do solo e, nas subparcelas, os níveis de compactação.

Os tratamentos foram constituídos por três implementos de preparo do solo $\left(\mathrm{IP}_{1}=\right.$ grade aradora; $\mathrm{IP}_{2}=$ arado de aivecas, e $\mathrm{IP}_{3}=$ escarificador $)$ e quatro níveis de compactação $\left(\mathrm{NC}_{0}=\right.$ solo não trafegado $(1,53 \mathrm{MPa}) ; \mathrm{NC}_{3}=3$ passadas $(2,44 \mathrm{MPa}) ; \mathrm{NC}_{6}=6$ passadas $(2,82 \mathrm{MPa})$ e $\mathrm{NC}_{9}=9$ passadas de trator $(3,33 \mathrm{MPa}))$. No dia $1^{\circ}$ de março de 2013 , foi realizada a operação com os implementos de preparo de solo e, no dia 27 de março de 2013, foram aplicados os níveis de compactação. Para a simulação dos níveis de compactação, o trator trafegou por toda a parcela experimental, sendo que o número de passadas variou conforme os tratamentos.

A operação de semeadura foi realizada no dia 28 de março de 2013, utilizando o híbrido de milho DKB390PRO, sendo realizada de forma mecânica, utilizando-se de semeadora adubadora regulada para distribuir 7,6 sementes por metro. Quando a cultura apresentou três folhas completamente expandidas, foi realizado desbaste, objetivando-se um estande final de 6 plantas por metro. Estas foram utilizadas para a avaliação dos atributos e das características estabelecidos. Cada parcela, com quatro fileiras espaçadas de $0,9 \mathrm{~m}$ com 3,5 $\mathrm{m}$ de comprimento, ocupou área de 12,6 $\mathrm{m}^{2}$. A área útil da parcela foi de $6,3 \mathrm{~m}^{2}$ (duas fileiras centrais).

Realizou-se adubação de semeadura com $400 \mathrm{~kg} \mathrm{ha}^{-1}$ da fórmula 06-24-12 (NPK) contendo $6 \%$ de Ca e $6 \%$ de S; além de adubações de cobertura, utilizando-se de $150 \mathrm{~kg} \mathrm{ha}^{-1}$ da fórmula 20-00-20 (NPK), quantidade esta fracionada em três aplicações, sendo as aplicações aos 15; 25 e 35 dias após a emergência (DAE). O controle de plantas daninhas foi realizado sempre que necessário, por meio de capinas manuais, objetivando manter a cultura livre de competição, e não foi necessário realizar o controle de pragas, devido à tecnologia embutida na semente do híbrido utilizado.

$\mathrm{Na}$ entrelinha da cultura, em um ponto por subparcela, foram avaliados nas camadas de 0,00-0,10; 0,10-0,20; 0,20-0,30 e 0,30-0,40 m os seguintes atributos físicos do solo: densidade do solo (Ds) pela metodologia do anel volumétrico (EMBRAPA, 2011); porosidade total (Pt) e, resistência à penetração $(\mathrm{RP})$, utilizando-se de penetrômetro de impacto modelo IAA/Planalsucar; com os dados sendo transformados em MPa, por meio da [eq. (1)].

$$
\mathrm{RP}=0,56+0,698 \mathrm{~N}
$$

em que,

$\mathrm{RP}$ - resistência mecânica à penetração, $\mathrm{MPa}, \mathrm{e}$

$\mathrm{N}$ - número de impactos. 
$\mathrm{Na}$ colheita do experimento, que foi realizada no dia 15 de julho de 2013, avaliaram-se os atributos agronômicos: matéria seca das raízes (MSR), matéria seca das plantas (MSP) e produtividade de grãos (PG). Para a determinação da MSR, coletaram-se raízes a $0,15 \mathrm{~m}$ de profundidade, empregando-se o método do monólito (BARBOSA \& SANTOS, 2009). A PG foi obtida aferindo-se a massa de grãos, sendo considerada umidade padrão de $13 \%$. Para a determinação da MSP, utilizaram-se plantas inteiras que foram levadas para estufa com ventilação forçada a $65^{\circ} \mathrm{C}$, até atingirem peso constante.

Os dados dos atributos físicos do solo e os agronômicos da cultura foram submetidos à análise de variância e, posteriormente, ao teste de Tukey, a 5\% para comparação de médias. Quando, da ocorrência de significância do fator quantitativo, promoveu-se a análise de regressão, que foi ajustada para os valores de RP encontrados em função dos níveis de compactação.

\section{Densidade do solo $(\mathrm{Ds})$, porosidade total $(\mathrm{Pt})$ e resistência à penetração $(\mathrm{RP})$}

Os implementos de preparo do solo influenciaram a Ds e a Pt apenas na camada de 0,00-0,10 m. Os níveis de compactação influenciaram a Ds nas camadas de 0,00-0,10 m e 0,30-0,40 m, a Pt na camada de 0,00-0,10 me a RP até à profundidade de 0,30 m (Tabela 2).

TABELA 2. Resumo da análise de variância para a densidade do solo (Ds), porosidade total (Pt) e resistência à penetração (RP), nas camadas do Argissolo Amarelo em função dos implementos de preparo do solo e dos níveis de compactação. Variance analysis summary for soil bulk density (Ds), total porosity (Pt) and resistance to penetration (RP) at diffe rent depth of a Yellow Argisol (Ultisol) as a function of tillage implement type and compaction levels.

\begin{tabular}{|c|c|c|c|c|}
\hline \multirow{2}{*}{ Causas de Variação } & \multicolumn{4}{|c|}{ Camadas do solo (m) } \\
\hline & $0,00-0,10$ & $0,10-0,20$ & $0,20-0,30$ & $0,30-0,40$ \\
\hline & \multicolumn{4}{|c|}{ Densidade do solo $\left(\mathrm{Mg} \mathrm{m}^{-3}\right)$} \\
\hline IP & $27,12^{*}$ & $0,58^{\mathrm{ns}}$ & $2,71^{\mathrm{ns}}$ & $0,50^{\mathrm{ns}}$ \\
\hline $\mathrm{NC}$ & $7,50 *$ & $0,96^{\mathrm{ns}}$ & $0,99^{\mathrm{ns}}$ & $3,10^{*}$ \\
\hline IP $x$ NC & $1,75^{\mathrm{ns}}$ & $0,65^{\mathrm{ns}}$ & $1,05^{\mathrm{ns}}$ & $1,23^{\mathrm{ns}}$ \\
\hline DMS IP & 0,030 & 0,115 & 0,057 & 0,112 \\
\hline DMS NC & 0,094 & 0,073 & 0,062 & 0,075 \\
\hline C.V. $(\%)-$ IP & 1,60 & 5,88 & 2,95 & 5,93 \\
\hline C.V. $(\%)-\mathrm{NC}$ & 4,89 & 3,62 & 3,11 & 3,88 \\
\hline \multicolumn{5}{|c|}{ Porosidade total $\left(\mathrm{m}^{3} \mathrm{~m}^{-3}\right)$} \\
\hline IP & $12,42 *$ & $0,70^{\mathrm{ns}}$ & $0,24^{\mathrm{nS}}$ & $0,54^{\mathrm{nS}}$ \\
\hline $\mathrm{NC}$ & $7,36^{*}$ & $1,05^{\mathrm{ns}}$ & $0,23^{\mathrm{ns}}$ & $0,47^{\mathrm{ns}}$ \\
\hline IP $x$ NC & $1,68^{\mathrm{ns}}$ & $0,68^{\text {ns }}$ & $0,70^{\text {ns }}$ & $1,45^{\mathrm{ns}}$ \\
\hline DMS IP & 0,015 & 0,034 & 0,017 & 0,032 \\
\hline DMS NC & 0,032 & 0,030 & 0,023 & 0,029 \\
\hline C.V. $(\%)-$ IP & 4,88 & 12,01 & 5,93 & 10,12 \\
\hline C.V. $(\%)-\mathrm{NC}$ & 10,2 & 10,19 & 7,81 & 8,89 \\
\hline \multicolumn{5}{|c|}{ Resistência mecânica à penetração (MPa) } \\
\hline IP & $2,93^{\mathrm{ns}}$ & $4,24^{\mathrm{ns}}$ & $1,90^{\mathrm{ns}}$ & $1,06^{\mathrm{ns}}$ \\
\hline $\mathrm{NC}$ & $12,95^{*}$ & $10,44^{*}$ & $6,81 *$ & $2,66^{\mathrm{ns}}$ \\
\hline IP $x$ NC & $0,43^{\text {ns }}$ & $0,67^{\text {ns }}$ & $0,60^{\text {ns }}$ & $1,12^{\mathrm{ns}}$ \\
\hline DMS IP & 0,558 & 0,642 & 1,666 & 1,251 \\
\hline DMS NC & 0,997 & 0,836 & 1,192 & 1,189 \\
\hline C.V. $(\%)-$ IP & 25,06 & 26,60 & 46,38 & 29,66 \\
\hline C.V. $(\%)-\mathrm{NC}$ & 43,58 & 33,56 & 32,20 & 27,36 \\
\hline
\end{tabular}

ns = não significativo; * significativo a $5 \%$ de probabilidade; C.V. = Coeficiente de variação (\%); IP = Implementos de preparo do solo; $\mathrm{NC}=$ Níveis de compactação. DMS = Diferença mínima significativa. 
Os valores de Ds para os implementos de preparo do solo e para os níveis de compactação, considerando-se todas as camadas estudadas, variaram de 1,64 a 1,83 $\mathrm{Mg} \mathrm{m}^{-3}$, sendo superiores aos encontrados por CORTEZ et al. (2011), que oscilaram entre 1,30 e $1,43 \mathrm{Mg} \mathrm{m}^{-3}$ em trabalho desenvolvido no mesmo tipo de solo. Estes resultados estão próximos aos valores críticos de Ds propostos por ANDRADE et al. (2013), de 1,66 a 1,70 $\mathrm{Mg} \mathrm{m}^{-3}$ para solos de textura arenosa, quando a RP apresenta valor igual a $2 \mathrm{MPa}$.

$\mathrm{Na}$ camada de $0,00-0,10 \mathrm{~m}$, o arado gerou o maior valor de Ds $\left(1,76 \mathrm{Mg} \mathrm{m}^{-3}\right)$ (Figura 1), enquanto a grade proporcionou o menor valor $\left(1,69 \mathrm{Mg} \mathrm{m}^{-3}\right)$. Este fato pode ser justificado pela ação das grades aradoras que, além de destorroamento, provocam destruição dos agregados, deixando o solo mais solto e, provavelmente, também, porque o equipamento trabalhou a uma profundidade que variou entre 0,10-0,18 m. MAZURANA et al. (2011), em trabalho desenvolvido em Argissolo Vermelho-Amarelo, textura franco argiloarenosa, encontraram, para a camada de 0,03-0,12 m, menores valores de Ds quando o solo foi submetido ao preparo envolvendo grades, em função, provavelmente, da profundidade de trabalho do implemento, visto que NAGAHAMA et al. (2013) verificaram profundidade efetiva para a grade off-set com discos de $0,56 \mathrm{~m}$ igual a $0,20 \mathrm{~m}$.
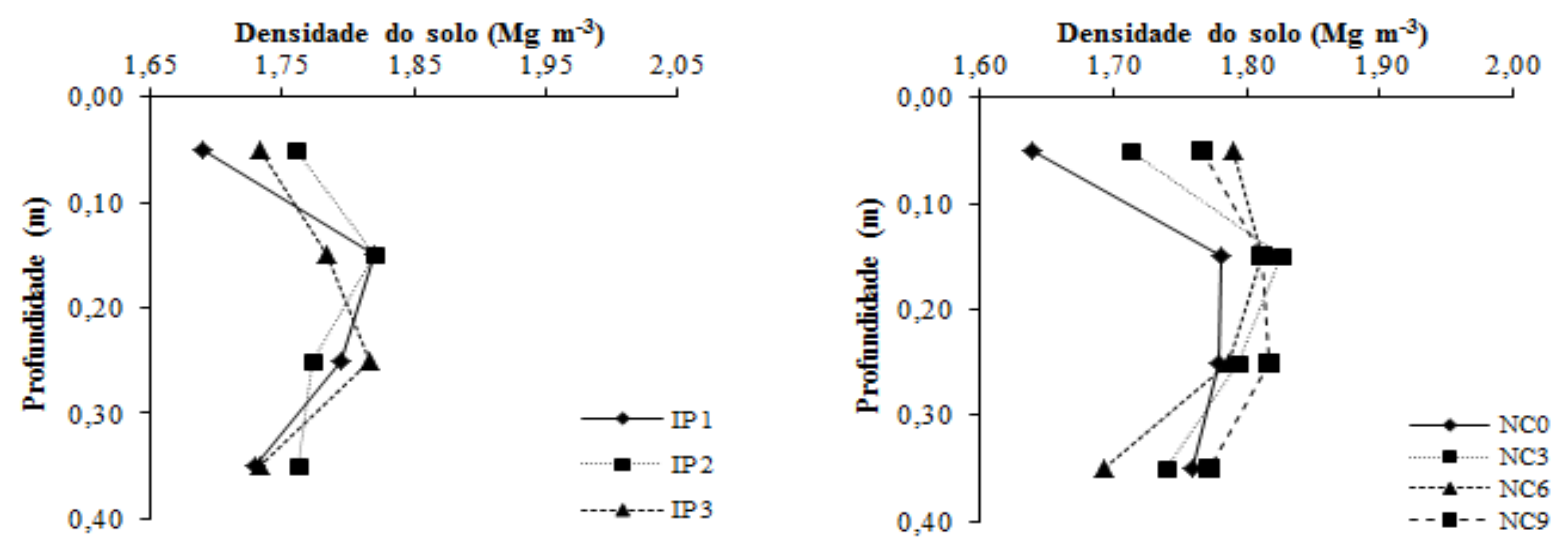

FIGURA 1. Densidade do solo em função dos implementos de preparo do solo $\left(\mathrm{IP}_{1}=\right.$ grade aradora; $\mathrm{IP}_{2}=$ arado de aivecas, e $\mathrm{IP}_{3}=$ escarificador $)$ e níveis de compactação $\left(\mathrm{NC}_{0}=\right.$ solo não trafegado; $\mathrm{NC}_{3}=3$ passadas; $\mathrm{NC}_{6}=6$ passadas, e $\mathrm{NC}_{9}=9$ passadas de trator). Soil bulk density as a function of tillage implement type $\left(\mathrm{IP}_{1}=\right.$ harrow disc, $\mathbf{I P}_{\mathbf{2}}=$ moldboard plow and $\mathrm{IP}_{3}=$ chisel plow) and compaction levels $\left(\mathrm{NC}_{0}=\right.$ no traffic; $\mathrm{NC}_{3}=3$ passes; $\mathrm{NC}_{6}=6$ passes and $\mathrm{NC}_{9}=9$ passes).

Em trabalho desenvolvido em Latossolo Amarelo dos Tabuleiros Costeiros cultivado com cana-de-açúcar, VASCONCELOS et al. (2014) observaram que os sistemas de manejo provocaram alterações nos atributos físicos do solo, aumentando a densidade e o grau de compactação, e reduzindo a condutividade hidráulica saturada, quando comparados com a mata nativa.

Para os níveis de compactação, o $\mathrm{NC}_{0}$ proporcionou valor médio de $\mathrm{Ds}\left(1,64 \mathrm{Mg} \mathrm{m}^{-3}\right)$ inferior aos $\mathrm{NC}_{6}\left(1,79 \mathrm{Mg} \mathrm{m}^{-3}\right)$ e $\mathrm{NC}_{9}\left(1,78 \mathrm{Mg} \mathrm{m}^{-3}\right)$ (Figura1); sendo estes valores de Ds considerados não críticos ao desenvolvimento de aspectos produtivos da cultura do milho, de acordo com REINERT et al. (2008), vis to que os mesmos puderam verificar ausência de raízes somente em perfis de solo com densidade acima de 1,85 a 1,92 $\mathrm{Mg} \mathrm{m}^{-3}$. Na camada de 0,30-0,40 m, as médias observadas no $\mathrm{NC}_{0}$ e $\mathrm{NC}_{3}$ não diferem estatisticamente; entretanto, o $\mathrm{NC}_{6}$ diferiu do $\mathrm{NC}_{9}$ (Figura 1). Segundo SILVA et al. (2011), estes valores de Ds em superfície, provavelmente, ocorreram em função de os níveis de pressão aplicados serem maiores do que a capacidade de suporte do solo.

Observou-se que a maior Pt ocorreu na camada de 0,00-0,10 m com uso de escarificador (Figura 2). MAZURANA et al. (2011), trabalhando em Argilosso Vermelho-Amarelo, textura franco argiloarenosa, com sistemas de preparo do solo, encontraram maiores valores de $\mathrm{Pt}$ 
na camada de 0,12-0,20 m ao utilizar escarificadores, devido ao aumento de volume de macroporos. Para TRINDADE et al. (2010), o efeito do preparo sobre os valores de porosidade pode ser pouco evidente, uma vez que a quantidade de água disponível no solo pode estar associada a valores de matéria orgânica e microporosidade, principalmente em Argissolos.
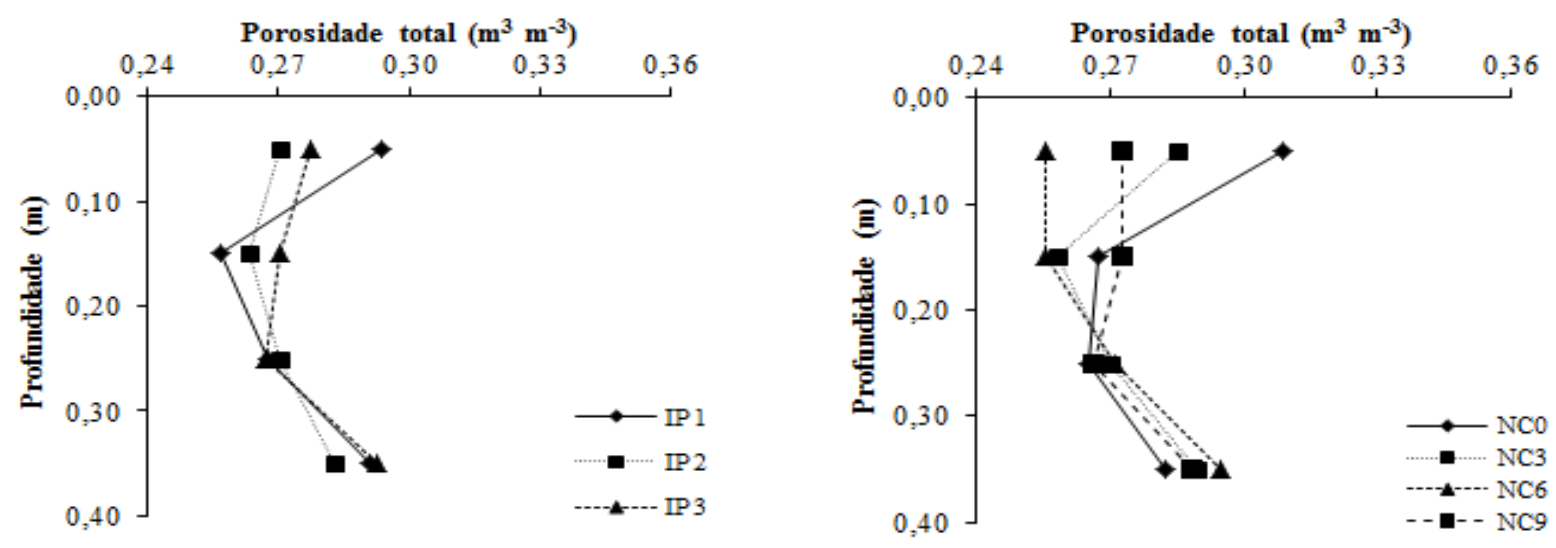

FIGURA 2. Porosidade total em função dos implementos de preparo do solo $\left(\mathrm{IP}_{1}=\right.$ grade aradora; $\mathrm{IP}_{2}=$ arado de aivecas, e $\mathrm{IP}_{3}=$ escarificador $)$ e níveis de compactação $\left(\mathrm{NC}_{0}=\right.$ solo não trafegado; $\mathrm{NC}_{3}=3$ passadas; $\mathrm{NC}_{6}=6$ passadas, e $\mathrm{NC}_{9}=9$ passadas). Soil total porosity as a function of tillage implement type $\left(\mathrm{IP}_{1}=\right.$ harrow disc, $\mathrm{IP}_{\mathbf{2}}=$ moldboard plow and $\mathrm{IP}_{3}=$ chisel plow $)$ and compaction levels $\left(\mathrm{NC}_{0}=\right.$ no traffic; $\mathrm{NC}_{3}=3$ passes $; \mathrm{NC}_{6}=6$ passes and $\mathrm{NC}_{9}=9$ passes)

$\mathrm{O} \mathrm{NC}_{0}$ (solo não trafegado) apresentou maior valor de $\mathrm{Pt}$, valor superior aos dos tratamentos $\mathrm{NC}_{3}, \mathrm{NC}_{6}$ e $\mathrm{NC}_{9}$, sendo estes três últimos iguais (Figura 2). Segundo ROSA et al. (2012), alterações de atributos físicos nas camadas mais profundas, como aumento de Ds e redução de macroporosidade, geradas pelo tráfego de máquinas, evidenciam a influência destas alterações até essas camadas, por meio da resistência mecânica à penetração.

Os níveis de compactação provocaram aumento na RP até à profundidade de $0,30 \mathrm{~m}$ (Figura 3). BEUTLER et al. (2009) verificaram, em Argissolo Vermelho-Amarelo arênico, submetido a intensidades de tráfe go, aumento da RP até $0,25 \mathrm{~m}$.

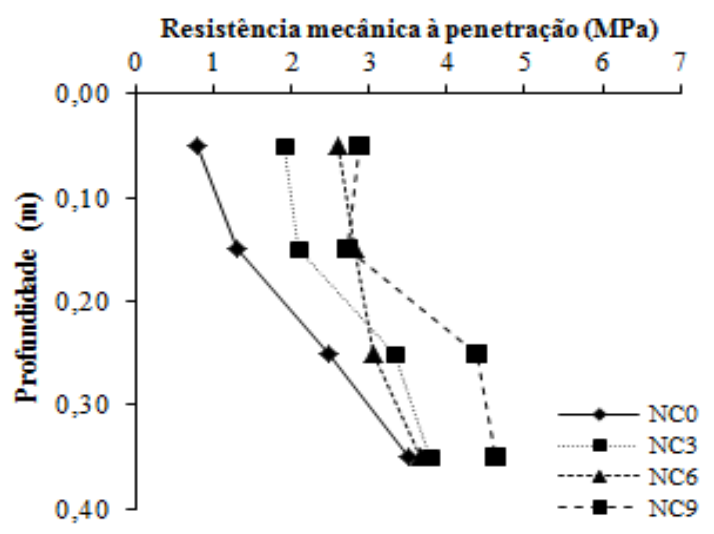

FIGURA 3. Resistência à penetração em função dos níveis de compactação $\left(\mathrm{NC}_{0}=\right.$ solo não trafegado; $\mathrm{NC}_{3}=3$ passadas; $\mathrm{NC}_{6}=6$ passadas, e $\mathrm{NC}_{9}=9$ passadas). Soil mechanical resistance to penetration as a function of compaction levels $\left(\mathrm{NC}_{0}=\right.$ no traffic; $\mathrm{NC}_{3}=3$ passes; $\mathrm{NC}_{6}=6$ passes and $\mathrm{NC}_{9}=9$ passes)).

Para a camada de $0,00-0,10 \mathrm{~m}, \mathrm{o} \mathrm{NC}_{0}$ (Figura 3 ) proporcionou o menor valor de $\mathrm{RP}(0,79$ $\mathrm{MPa})$, diferindo dos demais. $\mathrm{O} \mathrm{NC}_{3}(1,92 \mathrm{MPa})$ apresentou média igual ao $\mathrm{NC}_{6}(2,60 \mathrm{MPa})$ e ao $\mathrm{NC}_{9}(2,88 \mathrm{MPa})$. Apenas o $\mathrm{NC}_{0}$ e o $\mathrm{NC}_{3}$ apresentaram valores de $\mathrm{RP}$ menores que 2,0 $\mathrm{MPa}$, sendo 
que o tráfego do trator proporcionou incremento de 143; 229 e 264\%, respectivamente, para $\mathrm{NC}_{3}$, $\mathrm{NC}_{6}, \mathrm{NC}_{9}$ na RP. Pode-se observar que as maiores variações de RP foram encontradas na camada de 0,00-0,10 m (Figura 3). Segundo COUTO et al. (2013), aumento do grau de compactação induz à redução linear da macroporosidade, da condutividade hidráulica saturada e aumento da resistência à penetração.

Na camada de $0,10-0,20 \mathrm{~m}$, apenas no solo não trafegado $\left(\mathrm{NC}_{0}=1,30 \mathrm{MPa}\right)$, observaram-se valores de $\mathrm{RP}$ menores do que 2,0 $\mathrm{MPa}$ (Figura 3), não diferindo do $\mathrm{NC}_{3}=2,09 \mathrm{MPa}$, e diferindo dos demais tratamentos $\left(\mathrm{NC}_{6}=2,82 \mathrm{MPa}, \mathrm{NC}_{9}=2,70 \mathrm{MPa}\right)$. Para esta camada, o tráfe go do trator proporcionou incremento na RP de 61, 117 e 108\%, respectivamente, para 3; 6 e 9 passadas. ROSA et al. (2012), em trabalho desenvolvido em Argissolo Vermelho-Amarelo, textura franco argiloarenosa, verificaram que o tráfego (4 e 8 passadas de máquina com massa de $10 \mathrm{Mg}$ ) gerou maiores valores de RP na camada de 0,05-0,15 m, independentemente do sistema de preparo utilizado.

Para a camada de $0,20-0,30 \mathrm{~m}, \mathrm{o} \mathrm{NC}_{0}, \mathrm{NC}_{6}$ e $\mathrm{NC}_{3}$ (Figura 3 ) apresentaram médias $(2,48 ; 3,05$ e 3,33 MPa, respectivamente) iguais, sendo que o $\mathrm{NC}_{9}$ apresentou o maior valor de $\mathrm{RP}(4,40 \mathrm{MPa})$. Para esta camada, o incremento na RP, em função do tráfego do trator, foi de $41 ; 34$ e $77 \%$, respectivamente, para 3; 6 e 9 passadas. Para a camada de 0,30-0,40 m, não foram observadas diferenças em função dos níveis de compactação impostos. PREVEDELLO et al. (2013) também não observaram diferenças significativas na RP abaixo da camada de $0,30 \mathrm{~m}$, em Argissolo Vermelho-Amare lo distrófico arênico, em função dos tratamentos utilizados.

Matéria seca das plantas (MSP), matéria seca de raízes (MSR) e produtividade de grãos (PG)

A RP influenciou todas as características avaliadas para a planta. Não houve interação entre os implementos de preparo do solo e a RP, para nenhuma das características da cultura (Tabela 3).

TABELA 3. Resumo da análise de variância para a matéria seca das plantas (MSP), matéria seca das raízes (MSR) e produtividade de grãos (PG), em função dos implementos de preparo do solo e a resistência mecânica à penetração. Variance analysis summary for plant (MSP), root (MSR) dry matter and grain yield (PG) as a function of tillage implement type and mechanical resistance to penetration.

\begin{tabular}{cccc}
\hline \multirow{2}{*}{ Causas de Variação } & \multicolumn{3}{c}{ Avaliações } \\
\cline { 2 - 4 } & MSP & MSR & PG \\
\hline IP & $0,84^{\mathrm{ns}}$ & $1,85^{\mathrm{ns}}$ & $3,01^{\mathrm{ns}}$ \\
RP & $14,65^{*}$ & $3,74^{*}$ & $5,09^{*}$ \\
IP x RP & $1,83^{\text {ns }}$ & $0,52^{\mathrm{ns}}$ & $0,44^{\mathrm{ns}}$ \\
DMS IP & 1,215 & 22,51 & 3,415 \\
DMS RP & 1,119 & 33,67 & 2,452 \\
\hline C.V. $(\%)-$ IP & 20,18 & 29,57 & 24,86 \\
C.V. $(\%)-$ RP & 18,69 & 49,18 & 17,77 \\
\hline
\end{tabular}

ns = não significativo; $*$ significativo a $5 \%$ de probabilidade; C.V. = Coeficiente de variação (\%); IP = Implementos de preparo do solo; NC = Níveis de compactação.

A MSP apresentou comportamento linear decrescente em função do aumento da RP a partir de 1,53 MPa, com redução de 39\%, quando es ta sofreu alteração de 1,53 para 3,33 MPa (Figura 4). FREDDI et al. (2009) também verificaram redução linear (26\%) na MSP da cultura do milho em Latossolo Vermelho, textura média, com a alteração da RP de 0,87 para 2,15 MPa, e ASSIS et al. (2014) verificaram tal redução em Argissolo Vermelho-Amarelo eutrófico, com valores de RP acima do limite crítico de 2,00 MPa. 

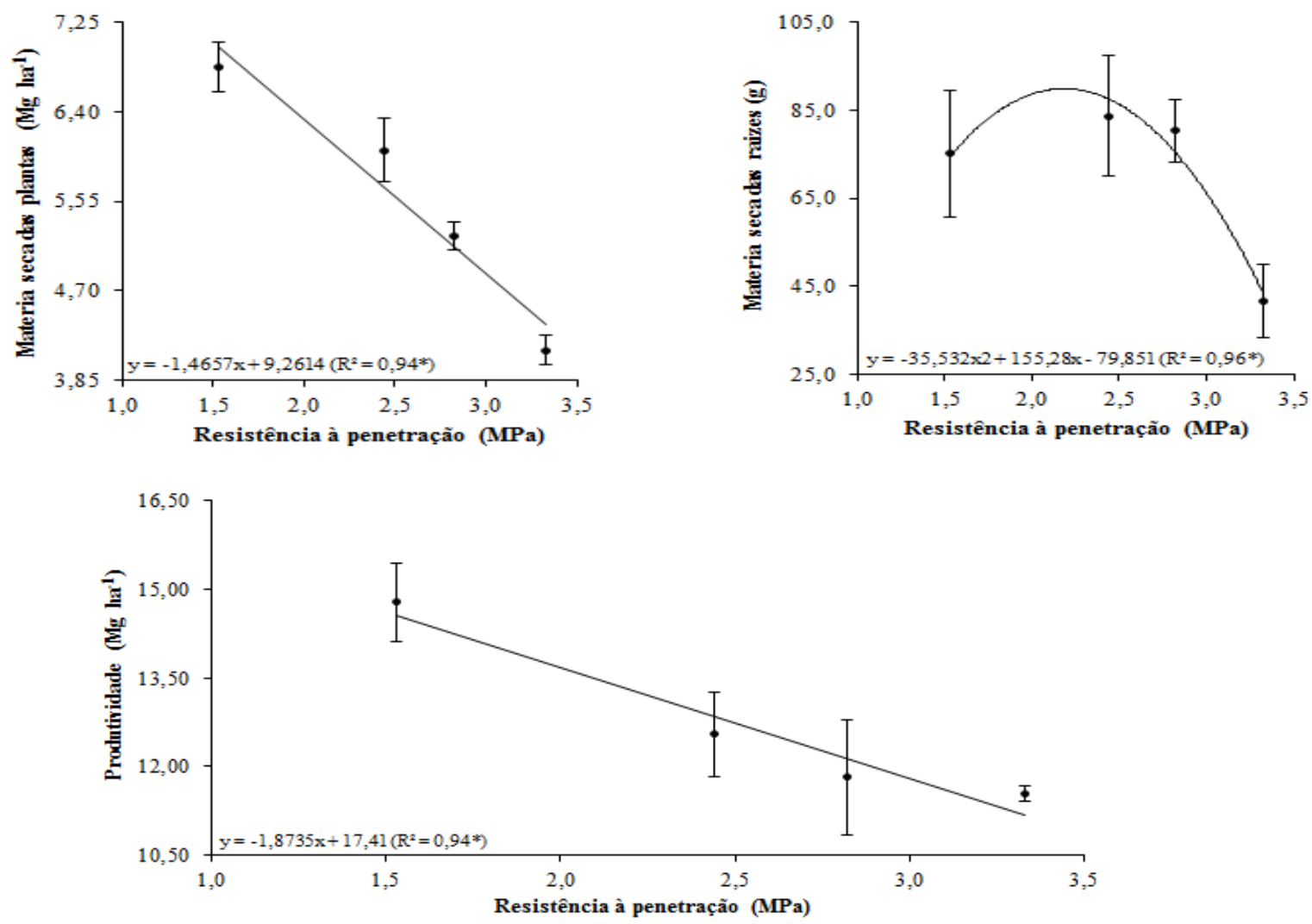

FIGURA 4. Regressões entre a resistência mecânica à penetração do Argissolo Amarelo e matéria seca das plantas, matéria seca das raízes e produtividade de grãos de milho. As barras referem-se aos erros padrões das médias. Regressions between mechanical resistance to penetration of a Yellow Argisol (Ultisol) and plant and root dry matter, as well as corn grain yield. The bars refer to the mean standard error.

A MSR apresentou comportamento quadrático em função do aumento da RP (Figura 4). Verificou-se que, até 2,18 MPa (ponto de máxima), houve aumento da MSR e, a partir deste valor, houve redução, podendo ser considerado como valor crítico para o desenvolvimento radicular e da parte aérea da cultura, neste solo em questão.

Verificaram-se reduções de $15 ; 20$ e $22 \%$, respectivamente, na produtividade de grãos de milho, quando comparado $\mathrm{NC}_{0}$ com $\mathrm{NC}_{3}, \mathrm{NC}_{6}$ e $\mathrm{NC}_{9}$ passadas de trator de 3,5 $\mathrm{Mg}$ de mas sa (Figura 4). O tráfego do trator aumentou a RP, reduzindo a possibilidade de absorção de água e de nutrientes, em função de menor expansão radicular. BEUTLER et al. (2009) verificaram situação semelhante em trabalho desenvolvido em Argissolo Vermelho-Amarelo arênico, onde o tráfe go de máquinas ( 8 passadas de trator de $8 \mathrm{Mg}$ ) reduziu a produtividade de grãos de milho em 22\%, quando comparado ao solo não trafegado. FREDDI et al. (2009), em Latossolo Vermelho, textura média, verificaram redução de $23 \%$ na produtividade do milho, quando a RP variou de 0,87 a 2,15 $\mathrm{MPa}$.

O aumento dos valores de RP, a partir de 1,53 MPa, reduziu linearmente a produtividade da cultura do milho (Figura 4). Entretanto, BEUTLER et al. (2009), em Argissolo Vermelho-Amarelo arênico, puderam observar que, a partir da RP de 0,91 $\mathrm{MPa}$, houve redução na produtividade de grãos de milho, e FREDDI et al. (2009), a partir de valor menor ainda, ou seja, 0,87 MPa. Portanto, em solos de textura arenosa, o nível crítico da RP que afeta a produtividade de grãos é maior do que no solo argiloso.

\section{CONCLUSÕES}

Os implementos de preparo do solo e os níveis de compactação influenciaram a densidade e a porosidade total, na camada de $0,00-0,10 \mathrm{~m}$. 

de $0,30 \mathrm{~m}$.

Os níveis de compactação provocaram aumento da resistência à penetração até à profundidade

$\mathrm{O}$ aumento da resistência à penetração acima de 1,53 MPa reduz linearmente a matéria seca de plantas e a produtividade de grãos de milho, e acima 2,18 MPa reduz a matéria seca de raízes.

\section{REFERÊNCIAS}

ANDRADE, R.S.; STONE, L.F.; GODOY, S.G. Estimativa da resistência do solo à penetração baseada no índice $S$ e no estresse efetivo. Revista Brasileira de Engenharia Agrícola e Ambiental, Campina Grande, v. 17, n. 9, p. 932-937, 2013.

ASSIS, E.B.; NUNES, M.C.M.; BARELLI, M.A.A.; SEABRA JUNIOR, S.; SERAFIM, M.E. Resistência à penetração em Argissolo Vermelho-Amarelo sob pousio e diferentes culturas de cobertura. Enciclopédia Biosfera, Goiânia, v. 10, n. 19, p. 1668-1677, 2014.

BARBOSA, R.I.; SANTOS, J.R.S. Biomassa de raízes em ecossistemas de savana - Protocolo (Versão 2). Boa Vista: Instituto Nacional de Pesquisas da Amazônia, 2009. 15p. Programa de Pesquisa em Biodiversidade.

BEUTLER, A.N.; CENTURION, J.F.; MENGATTO, L.H.; ALVES, J.B.; W AGNER, G.P.C. Impacto do tráfe go de máquinas na qualidade física do solo e produtividade de milho em Argissolo. Acta Scientiatum. Agronomy, Maringá, v. 31, n. 2, p. 359-364, 2009.

CORTEZ, J.W.; ALVES, A.D.S.; MOURA, R.D.; OLSZEVSKI, N.; NAGAHAMA, H.J. Atributos físicos do Argis so lo Amarelo do semiárido nordestino sob sistemas de preparo. Revista Brasileira de Ciência do Solo, Viçosa, v. 35, p. 1207-1216, 2011.

COUTO, R.F.; REIS, E.F.; VIANA, P.M.F.; HOLTZ, V.; OLIVEIRA, L.A.; ALVES, S.M.F. Compactação e recalque superficial de um Latossolo Vermelho em condição de campo e laboratório. Revista Brasileira de Engenharia Agrícola e Ambiental, Campina Grande, v. 17, n. 11, p. 1239-1245, 2013.

EMBRAPA - EMPRES A BRASILEIRA DE PESQUIS A AGROPECUÁRIA. Centro Nacional de Pesquisas de Solos. Manual de métodos de análise do solo. 2.ed. Rio de Janeiro, 2011. 230p.

EMBRAPA - EMPRES A BRASILEIRA DE PESQUIS A AGROPECUÁRIA. Centro Nacional de Pesquisas de Solos. Sistema B rasileiro de Classificação de Solos. 3.ed. Brasília, 2013. 353p.

FREDDI, O.S.; CENTURION, J.F.; DUARTE, A.P.; LEONEL, C.L. Compactação do solo e produção de cultivares de milho em latossolo vermelho: I - características de planta, solo e índice S. Revista Brasileira de Ciência do Solo, Viçosa, v.33, n.4, p. 793-803, 2009.

LIMA, C.L.R.; REINERT, D.J.; REICHERT, J.M.; SUZUKI, L.E.A.S. Produtividade de culturas e resistência à penetração de Argissolo Vermelho sob diferentes manejos. Pesquisa Agropecuária Brasileira, Brasília, v.45, n.1, p.89-98, 2010.

MAZURANA, M.; LEVIEN, R.; MULLER, J.; CONTE, O. Sistemas de preparo de solo: alterações na estrutura do solo e rendimento das culturas. Revista Brasileira de Ciência do Solo, Viçosa, v.35, n.4, p.1197-1206, 2011.

MONTANARI, R.; PELLIN, D.M.P.; SILVA JUNIOR, C.A.; CARVALHO, M.P.; GIOIA, M.T.; DALCHIAVON, F.C.; GONZÁLEZ, A. P. Correlação entre produção de feijão e atributos físicos de um Latossolo em Mato Grosso do Sul. Revista Ceres, Viçosa, v.60, n.6, p.772-784, 2013.

NAGAHAMA, H.J.; CORTEZ, J.W.; PIMENTA, W.A.; PATROCÍNIO FILHO, A.P.; SOUZA, E.B. Desempenho do conjunto trator-equipamento em sistemas de preparo periódico no Argissolo Amarelo. Energia na Agricultura, Botucatu, v.28, n.2, p.79-89, 2013.

PREVEDELLO, J.; KAISER, D.R.; REINERT, D.J.; VOGELMANN, E.S.; FONTANELA, E.; REICHERT, J.M. Manejo do solo e crescimento inicial de Eucalyptus grandis Hill ex Maiden em Argissolo. Ciência Florestal, Santa Maria, v.23, n.1, p.129-138, 2013. 
REINERT, D.J.; ALBUQUERQUE, J.A.; REICHERT, J.M.; AITA, C.; ANDRADA, M.M.C. Limites críticos de densidade do solo para o crescimento de raízes de plantas de cobertura em Argissolo Vermelho. Revista Brasileira de Ciência do Solo, Viçosa, v.32, n.5, p.1805-1816, 2008.

ROSA, D.P.; REICHERT, J.M.; MENTGES, M.I.; ROSA, V.T.; VIEIRA, D.A.; REINERT, D.J. Demanda de tração e propriedades físicas de um Argissolo em diferentes manejos e intensidades de tráfe go. Pesquisa Agropecuá ria B rasileira, Brasília, v.47, n.1, p.118-126, 2012.

SILVA, A.R.; DIAS JUNIOR, M.S.; LEITE, F.P. Avaliação da intensidade de tráfego e carga de um Forwarder sobre a compactação de um Latossolo Vermelho-Amarelo. Revista Árvore, Viçosa, v.35, n.3, p.547-554, 2011.

TOIGO, S.; BRAIDA, J.A.; POSSENTI, J.C.; BRANDELERO, E.M.; BAESSO, M.M. Atributos físicos de um Nitossolo Vermelho cultivado com trigo, em sistema plantio direto, submetido à compactação e escarificação. Engenharia na Agricultura, Viçosa, v.23, n.1, p.19-28, 2015.

TRINDADE, E.F.S; CARVALHO, E.J.; CORRÊA, P.C.S. Comportamento físico-hídrico de um Argissolo Amarelo distrófico sob diferentes sistemas de manejo no nordeste paraense. Ciência \& Desenvolvimento, Belém, v.5, n.9, p.103-114, 2010.

VALICHESKI, R.R.; GROSSKLAUS, F.; STÜMER, S.L.K.; TRAMONTIN, A.L.; BAADE, E.S.A.S. Desenvolvimento de plantas de cobertura e produtividade da soja conforme atributos físicos em solo compactado. Revista Brasileira de Engenharia Agrícola e Ambiental, Campina Grande, v.16, n.9, p.969-977, 2012.

VASCONCELOS, R.F.B.; SOUZA, E.R.; CANTALICE, J.R.B.; SILVA, L.S. Qualidade física de Latossolo Amarelo de tabuleiros costeiros em diferentes sistemas de manejo da cana-de-açúcar.

Revista Brasileira de Engenharia Agrícola e Ambiental, Campina Grande, v.18, n.4, p.381-386. 2014. 